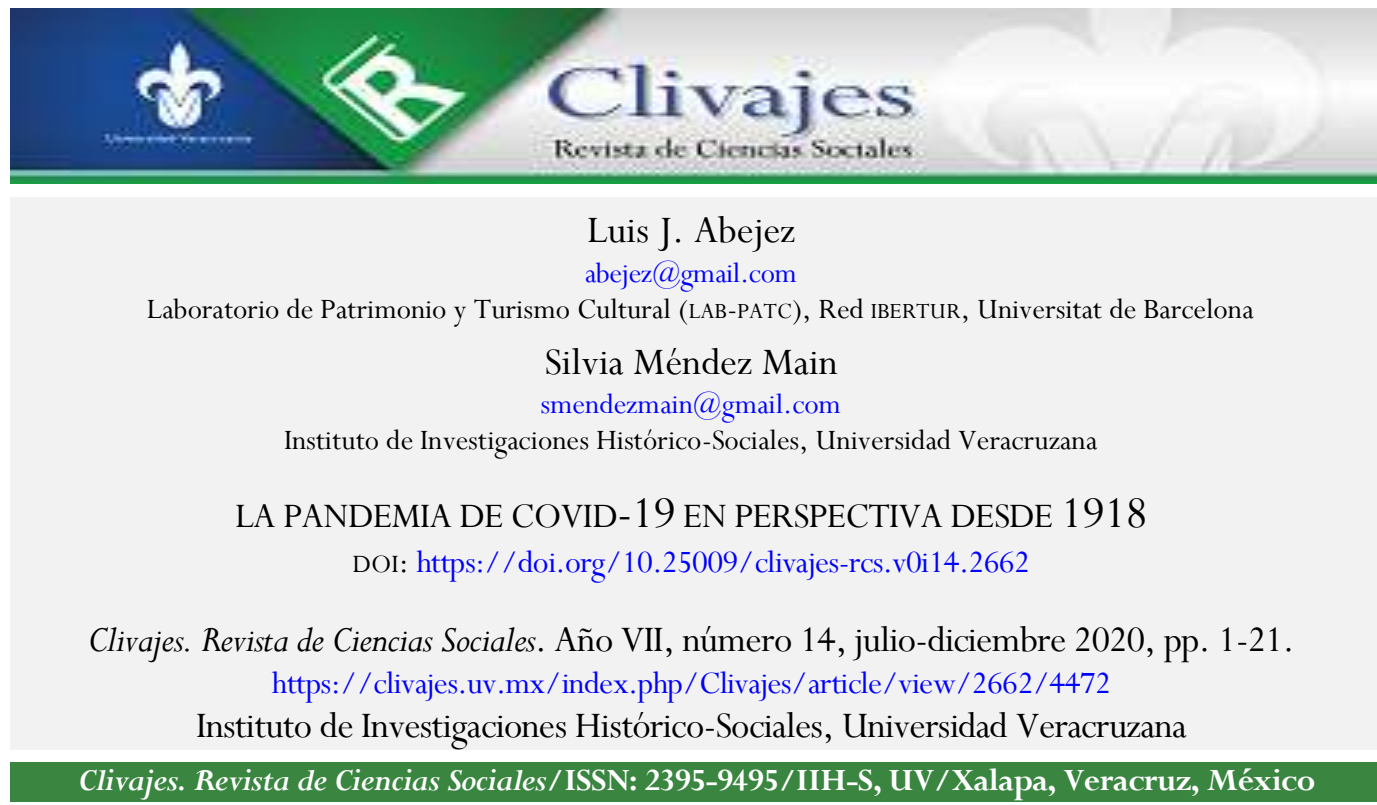

Recibido: 06/08/2020

Aceptado: 20/08/2020

Dictaminado: 09/12/2020 


\title{
LA PANDEMIA DE COVID-19 EN PERSPECTIVA DESDE 1918
}

\author{
Luis J. Abejez y Silvia Méndez Main**
}

\begin{abstract}
Resumen
La pandemia de influenza de 1918 ha sido una de las más devastadoras catástrofes en la historia de la humanidad. Algunas de sus características han hecho de ella una referencia prácticamente obligada al momento de abordar el estudio y análisis de otras epidemias y pandemias, anteriores o posteriores. Cual fantasma de las navidades pasadas, la irrupción de la pandemia de covid-19, a principios de 2020, provocó la reaparición de situaciones, actitudes y consecuencias que se consideraban propias de otras épocas. La nueva realidad impuesta por la enfermedad nos ha puesto a sociedades y personas frente a un espejo cuyo reflejo contiene ecos de antaño y del que, por lo general, no salimos especialmente favorecidos. En este trabajo proponemos una breve reflexión sobre algunos de los muchos aspectos presentes en la calidoscópica línea que une, tanto a escala individual como a escala colectiva, la pandemia de 1918 con la de 2020.
\end{abstract}

Palabras clave: Covid-19, Influenza, Pandemia, Epidemia, Sistema de salud

\section{THE COVID-19 PANDEMIC IN PERSPECTIVE SINCE 1918: A GENERAL REFLECTION}

\section{Summary}

The 1918 influenza pandemic was one of the most devastating catastrophes in human history. Some of its unique characteristics have made it a practically obligatory reference when addressing any study and analysis of other epidemics and pandemics, before or after. Like a ghost of last Christmas, the irruption of the covid-19 pandemic, in early 2020, caused the reappearance of situations, attitudes and consequences that were considered typical of other times. The new reality imposed by the disease has placed us, societies and individuals, in front of a mirror whose reflection contains echoes of yesteryear and from which, in general, we are not particularly favored. This paper proposes a brief reflection on some of the many aspects present in the kaleidoscopic line that links, both on an individual and collective scale, the pandemic of 1918 with that of 2020.

Keywords: Covid-19, Influenza, Pandemic, Epidemic, Health system

\section{LA PANDÉMIE PAR COVID-19 EN PERSPECTIVE DEPUIS 1918 : UNE RÉFLEXION GÉNÉRALE}

\section{Résumé}

La pandémie de grippe de 1918 a été une des plus dévastatrice catastrophes dans l'histoire de l'humanité. Certaines de ses caractéristiques uniques ont fait d'elle une référence littéralement obligée au moment d'aborder n'importe quelle étude et analyse d'autres épidémies et des pandémies antérieures ou postérieures. Tel que fantôme de noël, l'irruption de la pandémie de covid -19 au début de l'année 2020, a provoqué la réapparition de situations, attitudes et conséquences qui étaient considérées propres d'autres époques. La nouvelle réalité imposée par la maladie nous a mis à des sociétés et des personnes devant un miroir dont le reflet contient des échos d'autrefois qui ne nous favorisent pas du tout. Dans ce travail nous proposons une brève réflexion sur certains aspects parmi beaucoup d'autres présents dans la caléidoscopique ligne qui unifie la pandémie de 1918 et celle de 2020 tant à l'échelle individuelle que la collective.

Mots clés : Covid-19, Grippe, Pandémie, Épidémie, Système de santé

\footnotetext{
* Doctor en Geografía e Historia por la Universidad de Barcelona. Profesor-investigador. Laboratorio de Patrimonio y Turismo Cultural (LAB-PATC), Red IBERTUR/Universitat de Barcelona. Contacto: abejez@gmail.com.

** Doctora en Historia y Estudios Regionales por la Universidad Veracruzana. Profesora-investigadora en el Instituto de Investigaciones Histórico-Sociales de la Universidad Veracruzana. Contacto: smendezmain@gmail.com.
} 


\section{INTRODUCCIÓN}

Desde la declaración sobre la existencia de la covid-19, a finales de diciembre de 2019, la enfermedad se transformó en una pandemia que hasta el momento ha causado el contagio de 110 millones de personas y la muerte de 2.5 millones de ellas en todo el mundo. Los gobiernos han confinado a sus ciudadanos en sus hogares o restringido su movilidad, a la espera de que la intensidad de la enfermedad disminuya, o bien una vacunación masiva haga remitir los casos en el corto plazo.

Las enfermedades han acompañado al ser humano a lo largo de su historia. Cuando el número de casos de una enfermedad se incrementa significativamente por encima de lo habitual en una determinada zona geográfica, se habla de epidemia; si afecta a amplias regiones geográficas, por ejemplo, varios continentes, se define como pandemia. De todas las pandemias padecidas por el mundo, la de influenza, en 1918, es probablemente la "madre de todas las pandemias" (Taubenberger \& Morens, 2006), toda vez que ha sido una de las más mortales y singulares de la historia.

Aquella auténtica catástrofe sanitaria y humanitaria provocó el contagio de un tercio de la población mundial, para entonces cerca de 500 millones de personas, y la muerte de entre 50 y 100 millones de éstas (Johnson \& Mueller, 2002). A la postre, sus características particulares ${ }^{1}$ la convirtieron en un suceso extraordinario como objeto de estudio, pero también como referencia, por lo que además de "madre" es considerada una "maestra". Desde el último tercio del siglo XX, la pandemia de influenza se transformó en una fuente de información y comparación para la investigación y análisis de epidemias anteriores y posteriores; para el diseño de estrategias frente a nuevos brotes, y para estudiar la implementación de medidas, acciones, tratamientos, etc., o predecir riesgos potenciales, con base en conocimientos sobre cómo se generan los virus causantes, entre otros objetivos (García Sastre \& Whitley, 2006; Álvarez et al., 2009; Acuña, Castañeda \& Chowell, 2011; Simonsen et al., 2018).

Los primeros trabajos acerca de la pandemia de 1918 fueron de tipo médico y epidemiológico, inmediatos o casi coetáneos con la enfermedad, a los que siguieron

\footnotetext{
${ }^{1}$ La pandemia de influenza de 1918 fue causada por un virus (H1N1), hasta ese momento desconocido, del que derivan casi todos los casos de influenza $A$ ocurridos desde entonces; se produjo en una rápida sucesión de tres oleadas, que en algunos lugares se dieron en menos de un año, siendo la segunda ola la más virulenta y mortal; presentó un patrón de mortalidad inusual, centrado sobre todo en los adultos jóvenes; tuvo altas tasas de morbilidad, mortalidad y letalidad, y una alta incidencia de infecciones bacterianas secundarias como causa principal de muerte (Crosby, 1989; Taubenberger \& Morens, 2006).
} 
varias décadas de total desinterés. En comparación, a lo largo del siglo Xx se publicaron más estudios sobre la Peste Negra medieval, que sobre la pandemia de 1918. La "pandemia olvidada" (Crosby, 2003) apenas fue objeto de investigaciones médicas, científicas o históricas hasta la segunda mitad del siglo XX. Los brotes de influenza de 1957-1959 (gripe asiática) y de 1968 (gripe de Hong-Kong), los inicios de la epidemia de SIDA (Síndrome de Inmunodeficiencia Adquirida), en la década siguiente, y el importante incremento de nuevos brotes epidémicos, a partir de la década de 1990 (ébola, gripe aviar, SARS, gripe porcina, MERS -Síndrome Respiratorio por Coronavirus de Oriente Medio, etc.), hicieron resurgir el interés por su estudio, que se debatió entre tratarla como un episodio epidemiológico, un evento dramático, una crisis social y de salud pública o como objeto de investigación científica directa (Phillips, 2014).

En las últimas décadas, una "segunda ola" historiográfica ha cambiado sustancialmente la manera de enfocar su estudio. Se ha superado el énfasis en la cuantificación de la mortalidad, la búsqueda del origen del virus o sus consecuencias en el contexto histórico global, para adquirir mayor peso como tema de investigación histórica (Phillips, 2014), esta vez focalizada en el contexto humano, en los efectos sociales que tuvo en la población y en cómo ésta afrontó la enfermedad.

La actual pandemia de covid-19 ha generado, en pocos meses, un volumen ingente de publicaciones que tratan de analizar la enfermedad y sus múltiples facetas. ${ }^{2}$ Igualmente, ha puesto de manifiesto, una vez más, la fragilidad de la condición humana ante las epidemias, cuya súbita y mortal aparición deja un rastro de miedo, angustia y vulnerabilidad. En estos días de incertidumbre y desconcierto, los científicos y los medios de comunicación vuelven nuevamente la mirada a 1918; sin embargo, ¿realmente pueden compararse ambos episodios? ¿Se aprendió algo de aquella experiencia?

La línea que asocia la pandemia de 1918 con la actual es sumamente amplia, diversa y compleja de abordar, debido a los casi infinitos temas que pueden relacionarlas. Con la mirada puesta en el impacto que la pandemia de 1918 tuvo a escala individual y colectiva, en este trabajo proponemos una reflexión general sobre varios de los aspectos de dicha relación, aspectos que, entendemos, no sólo permiten comprender qué sucedió hace poco más de un siglo, sino, sobre todo, qué está sucediendo en estos momentos.

\footnotetext{
${ }^{2}$ A un año del surgimiento de la pandemia, la base de datos PubMed recoge más de 100000 publicaciones con la entrada “COVID-19”.
} 


\section{PEDRO Y EL LOBO O LA DESESPERACIÓN DE CASANDRA}

En 1918, una gran parte del mundo estaba en guerra. Se libraba el último año de la Gran Guerra (1914-1918), la Primera Guerra Mundial, y amplias regiones sufrían sus dramáticas consecuencias. La Revolución rusa daba sus primeros pasos y el país entraba en una sangrienta guerra civil, que tuvo inmediatas repercusiones desde Finlandia hasta Mongolia. México, por su parte, se encontraba agotado y arrasado tras ocho largos años de Revolución. Todos estos conflictos, y otros más, impactaron negativamente en la salud de la población. Las economías estaban volcadas en el esfuerzo de la guerra; las infraestructuras sanitarias se hallaban destruidas o gravemente afectadas; los médicos y sanitarios servían en los diferentes frentes; millones de personas fueron movilizadas y otras tantas desplazadas de sus hogares, todas en movimiento o hacinadas en barcos, campamentos y ciudades. El hambre y la miseria eran habituales. De una manera u otra, y en mayor o menor medida, todos estos factores eran compartidos por un gran número de países (Erkoreka, 2009; Wever \& van Bergen, 2014), situación que creó el caldo de cultivo ideal para la expansión de las enfermedades.

La pandemia de influenza apareció en marzo de 1918 en Estados Unidos, y en abril ya estaba presente en Europa (Erkoreka, 2009). Durante esa primera ola, que se extendió hasta el verano, las autoridades sanitarias no fueron conscientes del desastre que se avecinaba, incluso cuando tenían conocimiento del problema. Desde marzo, por ejemplo, el Public Health Weekly Reports (PHWR) notificó, casi semanalmente, casos de influenza en campamentos militares en Estados Unidos, pero no fue sino hasta el 21 de junio, cuando se publicó una escueta nota al respecto (PHWR, 1918a, p. 1003).

Quizá se pensara entonces que se trataba de una gripe estacional más, con la particularidad de que tenía una morbilidad y mortalidad más elevadas de lo habitual, aunque también es probable que directamente prefirieran ignorar, o incluso esconder, el peligro. En Gran Bretaña, Arthur Newsholme, de la Royal Society of Medicine, presentó, en julio de 1918, un “memorandum para uso público” destinado a combatir el brote, pero su distribución, según sus propias palabras, "no se consideró conveniente en ese momento", porque existían "circunstancias nacionales” en las que el deber principal era "continuar", incluso cuando se tratara de "riesgos para la salud y la vida" (Newsholme, 1919, p. 13).

En aquel momento histórico, la mayoría de la prensa de los países en conflicto colaboró en dicho cometido, al considerar que, en tiempo de guerra, tales noticias serían perjudiciales para la moral de la población. Hubo escasas excepciones. La neutralidad de 
España en la Gran Guerra permitió que su prensa informara de los estragos de la pandemia en el país, sobre todo en los meses de mayo y junio. De ahí que en varios países se bautizara con el nombre de "gripe o dama española" (Erkoreka, 2009). En México, aún en conflicto, las primeras noticias, nacionales y extranjeras, se publicaron a partir de abril de $1918,{ }^{3}$ aunque pasaron desapercibidas ante el volumen de noticias sobre la guerra en Europa, que acaparaba titulares y el interés del público, dejando incluso en segundo plano los acontecimientos nacionales (Cuenya, 2010).

No fue sino hasta principios de septiembre, cuando empezó la devastadora segunda ola de la pandemia, que los gobiernos comenzaron a percibir su verdadera magnitud, sobre todo al observar la cantidad de casos en Europa y especialmente en España. ${ }^{4}$ A mediados de mes, en Estados Unidos se publicó un amplio informe que describía la enfermedad y las medidas de protección y tratamiento que debían de adoptarse (PHWR, 1918b, pp. 1540 y ss.). La prensa internacional también comenzó a publicar noticias sobre la enfermedad, aunque tampoco debe extrañar que fuera entonces, dado que la Gran Guerra daba sus últimos estertores y estas noticias difícilmente podían alterar su desenlace.

La reacción en México fue algo más lenta. En septiembre, conociendo los casos de Europa, Estados Unidos e incluso de México, el interés político por la pandemia era inexistente, como lo fue a lo largo del año. En contraste con los intensos debates electorales, el tema no se mencionó en la Cámara de Diputados del Congreso de la Unión ni una sola vez en ese periodo. Incluso cuando los fallecidos comenzaron a multiplicarse, a partir de octubre, por todo el país, la clase política, salvo honrosas excepciones, parecía ajena. En realidad, las autoridades federales y estatales no tomaron verdaderas medidas preventivas contra la pandemia, sino hasta que se generalizó en octubre (Valdez, 2002; Cuenya, 2014, 2010), cuando ya era demasiado tarde. Según el Diario de los Debates de la Cámara de Diputados del Congreso de los Estados Unidos Mexicanos (DDCM), la primera mención de la pandemia en la Cámara de Diputados se hizo el 17 de octubre, pero no para discutir sobre la mortalidad que estaba causando o las

${ }^{3}$ El 24 de abril de 1918, El Informador, periódico de Guadalajara, publicó que una "gripa" causaba estragos en la ciudad y en México, aunque sin atribuirle un carácter alarmante. El día 30, comentó que revestía carácter grave, con consecuencias fatales en casos con neumonía, y que se incrementaba la mortalidad, por lo que apelaba a una mayor atención a la salud pública. El 29 y 31 de mayo, hizo eco de la epidemia en España, con más de 150000 afectados en Madrid, incluido el rey Alfonso XIII. El 21 de junio, informó de numerosas defunciones por un brote "parecido a la gripa” en Cananea, Sonora. El 28 de junio y el 6 de julio, describió cómo "la epidemia de gripa" había incapacitado a las tropas alemanas en el frente occidental.

${ }^{4}$ Sólo en España se notificó la afectación de 8 millones de personas (PHWR, 1918b, p. 1541). 
medidas para combatirla, sino para notificar la ausencia, por enfermedad, de un diputado de Campeche (DDCM, 1918).

Si bien el difícil contexto histórico de 1918 puede exculpar o justificar en parte a las naciones, por minusvalorar o ignorar los avisos y no haber estado preparadas cuando la segunda ola de la pandemia hizo su mortal aparición en otoño de ese mismo año, en 2020 la situación es muy diferente. Sin embargo, dicen, los países tampoco estaban preparados, pese a que las alarmas, aún más que en 1918, llevaban largo tiempo encendidas.

Desde mediados del siglo Xx, los brotes epidémicos han ido en aumento y la comunidad científica alertó constantemente sobre los riesgos de que se produjera una pandemia global y mortal. En 2004, se señaló que cada vez más evidencias apuntaban a la probabilidad de que nuevas enfermedades emergentes se produjeran por zoonosis, es decir, por patógenos que saltan de animales a humanos (Van der Giessen, Isken \& Tiemersma, 2004). En 2007, se advirtió sobre la capacidad de los coronavirus para sufrir recombinaciones genéticas y reaparecer, posiblemente, en nuevos brotes epidémicos (Cheng, Lau, Woo \& Yuen, 2007). En 2013, se presentó una recopilación-que inició en 2003- de nuevos coronavirus humanos de alto riesgo, sobre todo para los ancianos, y contra los cuales no había vacunas ni antivirales disponibles, por lo que se instó a desarrollar estrategias terapéuticas y preventivas aplicables a nuevas cepas emergentes (Graham, Donaldson \& Baric, 2013). En el mismo sentido, en 2015, se alertó acerca del riesgo potencial que el coronavirus de los murciélagos representaba para los seres humanos (Menachery et al., 2015). Todas las advertencias quedaron en el olvido.

En septiembre de 2019, pocos meses antes del estallido de la actual pandemia, la Organización Mundial de la Salud (OMS) publicó un informe, en el cual advirtió que el riesgo de una pandemia global estaba creciendo. Para entonces, la OMS vislumbraba peligrosamente "el espectro de una emergencia sanitaria mundial (...) la amenaza muy real de una pandemia fulminante, sumamente mortífera, provocada por un patógeno respiratorio que podría matar de 50 a 80 millones de personas y liquidar casi el 5\% de la economía mundial”. "El mundo no está preparado”, concluía, para una pandemia mundial de esa escala, que sería una catástrofe que desencadenaría caos, inestabilidad e inseguridad generalizadas (GPMB, 2019: 6). Esta advertencia también se ignoró.

En diciembre de 2019, varios hospitales de Wuhan (China) informaron sobre la incidencia de casos de neumonía de origen desconocido, aunque similares al Síndrome Respiratorio Agudo Severo (SARS-CoV) de 2002. La enfermedad se confirmó el 31 de diciembre. El 30 de enero de 2020, la OMs declaró la Emergencia de Salud Pública 
Internacional, y el 11 de marzo calificó la enfermedad de pandemia. En ese momento, había 118319 casos confirmados y 4292 fallecidos en todo el mundo (OMS, 2020). Italia se adelantó con una cuarentena el 9 de marzo, y España declaró el estado de alarma el día 13, con medidas de confinamiento, distanciamiento social y suspensión de actividades no esenciales, cuando contaba con 4209 casos y 120 fallecidos (MSCBS, Actualización n 43). Ese mismo día lo hizo Estados Unidos, aunque cada Estado fue aplicándolo a discreción. Francia decretó el confinamiento el día 17; Portugal, el 18, y Reino Unido, remiso en principio, el 23. México decretó la "emergencia sanitaria por causa de fuerza mayor" el 30 de marzo (DOF, 2020), con 1094 contagios y 28 muertes (Secretaría de Salud, 2020), tres meses después del comunicado de las autoridades chinas.

En los meses siguientes, el impacto de la enfermedad en los sistemas sanitarios ha llevado a buena parte de ellos casi al colapso, prácticamente han sido desbordados por falta de previsión en personal y material especializado. Las denuncias por estas carencias han sido constantes y generalizadas.

Si el tiempo de reacción y los medios son fundamentales en la contención de cualquier brote epidémico, sorprende la lentitud en la toma de decisiones ante la crisis actual, que ha repercutido en la preparación de los sistemas de salud. Sin embargo, como en 1918, casi ningún país ha aplicado medidas drásticas - con muchos matices--, sino hasta que el número de contagiados y fallecidos ha sido lo suficientemente significativo para obligar a los gobiernos a actuar. Si en 1918 la guerra fue la principal causa que condicionó la respuesta, en 2020 han sido otras consideraciones, eminentemente económicas, las que han prevalecido. Esto implica que las decisiones técnicas han estado a la sombra y bajo las órdenes de la voluntad política, por lo que siempre han ido por detrás del desarrollo de la enfermedad y nunca anticipándose a su evolución. Esto fue y ha sido un grave error, pero, ¿por qué ha sucedido?

\section{RACISMO, PREPOTENCIA Y EL IMPERIO DE LA ECONOMÍA}

Es un axioma en la política culpar a los demás de los fracasos propios. En una pandemia no hay culpas, sino responsabilidades; pero establecer una relación causal entre las poblaciones extranjeras y la propagación de enfermedades infecciosas, al tiempo que descarga las propias responsabilidades puede promover el miedo y el estigma irracionales (Hoppe, 2018). No es nada nuevo. Tucídides culpó a los espartanos de la peste de Atenas, Europa a los judíos de la Peste Negra y, en 1918, a pesar de que la influenza se extendió seguramente desde los Estados Unidos, cuando regresó de 
Europa, en su viaje de ida y vuelta, ya era la "gripe española". Nunca fue estadounidense.

Tal vez sea revelador, como señala Hoppe (2018, p. 1463), que no haya una epidemia conocida coloquialmente como "gripe estadounidense" o "gripe europea", lo cual podría interpretarse como resultado de patrones epidemiológicos en la propagación de la enfermedad, o como un reflejo de las desigualdades globales que permiten a los países poderosos responsabilizar de enfermedades y epidemias a otras naciones en lugar de a sí mismos.

Si en 1918 la pandemia fue de "gripe española", la de covid-19 ha sido "la epidemia de coronavirus de Wuhan". Por esta estigmatización, varios ciudadanos de origen chino, o físicamente semejantes, han sido agredidos en países occidentales (Francia, España, Italia, Estados Unidos, etc.), y un buen número de negocios regentados por estos ciudadanos tuvieron que cerrar "voluntariamente". ${ }^{5}$ A finales de enero de 2020, el foco de la pandemia se desplazó de China a Italia, pero ni los ristorantes ni las pizzerías cerraron, y no ha trascendido ninguna agresión a un ciudadano italiano por el simple hecho de serlo.

En los últimos meses, diferentes medios de comunicación y algunos gobernantes han acusado abiertamente a China de ocultar información. Dicen que, de haberse conocido, se habría evitado la propagación de la enfermedad. Incluso se ha acusado a la OMS de colaborar para retener la información y encubrir los fallos de las autoridades chinas, y hasta de falta de transparencia en la gestión de la pandemia, pero el mundo, como hemos visto, estaba más que avisado.

Con excepción de varios países asiáticos que, rápidamente, tras el comunicado emitido por el gobierno chino, el 31 de diciembre de 2019, comenzaron a tomar medidas de contención, la mayoría de los países del mundo han tardado más de dos meses, e incluso tres, en aplicarlas, y con diferencias extremas en cuanto a su carácter, firmeza y duración. En el caso de los llamados "países occidentales", es posible que la mezcla de una supuesta superioridad política, moral y tecnológica los haya llevado a minusvalorar la enfermedad y despreciar la experiencia de los países asiáticos, cayendo en una autocomplacencia que se ha mostrado casi suicida. En la reunión de responsables de los sistemas de salud del Centro Europeo para el Control y la Prevención de las Enfermedades (ECDC), celebrada el 18 y19 de febrero de 2020, pocos días antes del

\footnotetext{
${ }^{5}$ Sobre la actitud hacia ciudadanos de origen chino en Italia, véase Adja, Golinelli, Lenzi, Fantini \& Wu, 2020.
} 
gran estallido en Italia, el brote epidémico fue considerado de "bajo riesgo" para la población europea, subestimando su capacidad de transmisión y letalidad.

La prensa y los "expertos" ayudaron a minimizar el problema en algunos países. A diferencia de México, donde la prensa destacó desde los primeros momentos las diferencias de la actual enfermedad con la gripe común, la reacción en España fue muy diferente; por ejemplo, el 27 de febrero de 2020, en la Web de la Cadena SER (Justo, 2020) se comparó el número de contagios y muertes causadas por la covid-19 con los de la gripe común, sentenciando que: "se ha desatado una alarma social que, tal y como demuestran los datos, por el momento no está justificada”. Ese mismo día, otro medio destacó, en el mismo sentido: "Hay más muertes por gripe, y no crean tanta alarma, como el coronavirus" (Martín, 2020). Para algunos expertos, asimismo, "el número de casos exportados [desde China] es un goteo que los países ricos están preparados para afrontar", aunque "la situación de la vecina Italia lleva a replantearse la gravedad y las medidas necesarias ante una posible crisis" (Mitjá, 2020). ¿La situación en Italia? ¿Lo sucedido en China no era suficientemente alarmante?

El 21 de marzo de 2020, el periódico español El Confidencial tituló: “¿Mano dura china? No, gracias: así están derrotando estas democracias al coronavirus" (Pretel \& Escudero, 2020). Se refería a democracias asiáticas como Taiwán o Corea del Sur. Si la diferencia para luchar con éxito contra una epidemia reside en el sistema político, ¿qué ha fallado en las democracias occidentales? Se decía que las estrictas medidas de confinamiento impuestas en China suponían un atentado contra derechos fundamentales como la libertad de movimiento, lo cual equivale a afirmar que los virus se atienen a la ideología y las leyes humanas.

Aún inmersos en la pandemia y con rebrotes constantes, tanto en países democráticos como en los que no lo son, se puede afirmar que en los países occidentales se minusvaloró la covid-19, tal como sucedió en los primeros momentos con la pandemia de 1918; en un principio, estos países descartaron las medidas adoptadas por China -que más tarde se han generalizado--, debido a un complejo de superioridad que los llevó a sobrevalorar su capacidad para enfrentar la enfermedad. Las diferencias en el número de personas contagiadas y de muertos no se deben tanto a los sistemas políticos, sino a la responsabilidad social, colectiva e individual, que suele ser consecuente con el nivel cultural y educativo de los ciudadanos. ${ }^{6}$ No obstante, si

\footnotetext{
${ }^{6}$ En este sentido, cabe destacar que el 71\% de los muertos por covid-19 en México tenía un nivel de escolaridad de primaria o inferior, por lo que "puede asumirse una selectividad del padecimiento por nivel de escolaridad" (Hernández Bringas, 2020, p. 5).
} 
bien la ciudadanía es responsable de sus actos, la capacidad de respuesta de un país depende de la voluntad política, que es en gran medida ideológica, por lo que priman unos intereses sobre otros. En 1918 prevaleció la guerra; en 2020, la economía ha impuesto su criterio.

Hasta aquí, es posible decir que, en general, se ha priorizado lo económico por encima de la salud pública, como si ambos aspectos fueran autónomos y no estuviesen interrelacionados. El caso de España es significativo. Desde el primer diagnóstico positivo de covid-19 (el 31 de enero de 2020), las élites empresariales, la clase política y parte importante de la sociedad parecían más preocupadas por cómo podía afectar la enfermedad al turismo durante la Semana Santa, o a las Fallas de Valencia una semana después, que por el peligro potencial de permitir grandes aglomeraciones. Incluso cuando se suspendió el Mobile World Congress en Barcelona, el 12 de febrero de 2020, debido a la ausencia de expositores por miedo creciente a la pandemia, la decisión levantó agrias críticas en amplios sectores, sobre todo económicos. Se llegó a acusar a las multinacionales y a la propia organización de tener intereses velados; inclusive se acusó al gobierno municipal de obstaculizar la celebración por intereses políticos. El miedo no impidió, por lo contrario, que el $1^{\circ}$ de marzo se jugara, en el estadio Santiago Bernabéu de Madrid, el “clásico" entre Real Madrid y Fútbol Club Barcelona, con asistencia de casi 80000 espectadores. En una semana, los casos confirmados de covid-19 en Madrid pasaron de 29 el día 2, a 469 el día 9 (MSCBS, Actualizaciones n ${ }^{\circ} 34$ y 39).

Durante los meses de febrero y marzo, se llevaron a cabo miles de manifestaciones, reuniones políticas, culturales y religiosas, y actividades deportivas nacionales e internacionales en todo el mundo, sin comprender la magnitud que podía alcanzar la pandemia. La mayoría de las ciudades celebraron, por ejemplo, el Día de la Mujer el 8 de marzo con total normalidad. Otro ejemplo, localizado en la Ciudad de México, fue la celebración del Festival Iberoamericano de Cultura Musical Vive Latino, los días 13 y14 de marzo: pese a la presión social en contra, la gran afluencia de personas fue una "especie de burbuja ajena a los problemas" (Ibarra, 2020), ${ }^{7}$ y los ejemplos podrían multiplicarse.

\footnotetext{
${ }^{7}$ Según el portal oficial del Gobierno de México para la covid-19, hasta el 13 de marzo de 2020 se había reportado un total de 62 casos confirmados en la Ciudad de México. Quince días después del Festival, el 27 de marzo, la Ciudad alcanzaba 444 casos confirmados, 382 más que dos semanas antes, es decir, la cifra de contagiados se multiplicó por seis (CONACYT-CentroGeo-GeoInt-DataLab, 2020).
} 


\section{UNA CUESTIÓN SOCIAL}

La intromisión de la economía en la salud destaca el hecho de que las epidemias no son fenómenos estrictamente sanitarios, sino sucesos sistémicos, multifactoriales, de tipo causa/efecto y retroalimentados. Además de tener un impacto sobre la salud, sus consecuencias se reflejan a corto, mediano y largo plazo sobre todos los aspectos de la vida social, sean económicos, sociales, culturales e incluso psicológicos. Estos factores, intrínsecamente relacionados, determinan la salud de la población y, por tanto, influyen también en la aparición, propagación y contención de una epidemia o en las causas de muerte. Es por ello que la implementación de políticas sociales de carácter preventivo es el medio más eficaz para evitar las epidemias.

La desigualdad social, aún más que lo estrictamente biológico, determina el impacto de las enfermedades en la salud de una población o en un sector de ésta (Susser, Watson \& Hopper, 1985; Whitehead, 2000). Las epidemias evidencian y amplifican las contradicciones, los conflictos y las tensiones, pero también los déficits preexistentes. Las políticas económicas de austeridad, impuestas tras la crisis de 2009 en muchos países, se materializaron, entre otros aspectos, en recortes a los sistemas públicos de salud, de protección social y en la privatización de servicios asistenciales. Su impacto ha determinado no solamente la capacidad de respuesta del sistema público sanitario para afrontar la pandemia de covid-19, sino que ha tenido dramáticas consecuencias en el elevado número de defunciones que ésta ha producido, por ejemplo, en residencias de personas adultas mayores y personas con discapacidad o con enfermedades mentales; tal es el caso de la Comunidad de Madrid, España, abanderada en ese tipo de recortes y privatizaciones. Según el periódico El Español (Redacción, 2020), del 8 de marzo al 16 de junio de 2020, 5981 personas fallecieron por covid-19 o con síntomas compatibles en las mencionadas instituciones, lo que supone el 73,23\% del total de los ahí fallecidos durante ese periodo. Algunos de esos centros tuvieron que ser intervenidos, y en otros se han abierto investigaciones judiciales.

En 1918, los conflictos armados vigentes habían empeorado sustancialmente las condiciones de vida y sociosanitarias de una gran parte de la población mundial que ya vivía en una situación previa de miseria casi crónica, mermando aún más su capacidad para afrontar las enfermedades. En esas circunstancias, el mundo estaba en una situación de extrema vulnerabilidad, por lo que la pandemia se tradujo de inmediato en un elevado número de víctimas. Guerras y epidemias nunca han sido una buena combinación. La muerte y la pobreza llevaron a la desesperación, y la falta de una actuación política que 
protegiera a los más desfavorecidos les condujo a abrazar opciones políticas extremistas, como el fascismo, en la década de 1920. El resultado es bien conocido, pero no parece que los gobiernos actuales hayan aprendido esa lección. En 2020, toda una generación, que ya venía marcada por la crisis económica de 2009, se encuentra ahora en un nuevo escenario de recesión que golpea a los ya antes golpeados, incrementando aún más la desigualdad social, mientras la extrema derecha, populista y nacionalista, crece en el mundo: los ejemplos de Estados Unidos, Brasil, Chile, buena parte de los países europeos, etc. sirven de recordatorio.

\section{LA AMNESIA Y EL DOLOR}

La historia enseña que tras una catástrofe - y una epidemia es de las más devastadoras--, una y otra vez se produce una especie de amnesia colectiva que intenta borrar de la memoria todo rastro del horror vivido, en un intento por regresar lo antes posible a la normalidad previa. Como explica Carlos Pérez (2006): "la actualidad anodina trama su continuidad sobre el olvido de la catástrofe” (p. 192). Aunque esto, en verdad, nunca sucede.

Las epidemias muestran lo débil que puede ser la memoria colectiva. La "alarma social" ante la pandemia de influenza de 1918 se circunscribió al periodo en el que se produjo, sobre todo cuando la mortalidad se incrementó durante la segunda ola de otoño, que acumuló dos de cada tres del total de fallecidos. La prensa internacional, que anteriormente apenas había informado sobre la pandemia, comenzó a hacer eco de la enfermedad en esos meses de gran impacto. Cuando la tercera ola fue diluyéndose, a lo largo de 1919, las noticias también se diluyeron, al igual que la memoria por los muertos de la pandemia, los cuales se mezclaron y quedaron soterrados bajo la pérdida colectiva que supusieron las grandes mortandades causadas por las guerras. Cuando estas tormentas parecieron amainar, ¿quién no querría olvidar este periodo y todo lo que en él sucedió?

Todos querían, por tanto, pasar página, y la sociedad entró en una "nueva normalidad”. Los "locos años 20" simbolizan la alegría del superviviente, un carpe diem generalizado propio de una postguerra; un nuevo mundo de luces de neón, jazz y charlestón, pero también de sombras. El cine (El gabinete del doctor Caligari, Wiene, 1920; Metrópolis, Lang, 1927), y la literatura (El segundo advenimiento, Yeats, 1921; París era una fiesta, Hemingway, 1964; El gran Gatsby, Scott Fitzgerald, 1925) proyectó a la 
perfección aquel espíritu, sobre todo marcado por la guerra y no por la enfermedad, de la que nadie en público ni se acordaba ni quería acordarse. Cuando Vera Brittain (1935, p. 462) escribió que no quería formar parte de ese mundo "extraño, brillantemente iluminado", "diferente del que había conocido durante cuatro largos años (...) en el que las personas querían despreocuparse y olvidar”, se refería a los cuatro años de guerra en los que trabajó como enfermera voluntaria. El propio Crosby (1989, p. 315) señala esta desconcertante ausencia de la enfermedad, incluso en las obras de los más grandes escritores de la "generación perdida", como Hemingway, Scott Fitzgerald o John Dos Passos, entre otros, para los que la Gran Guerra fue "la experiencia central en sus vidas".

Sin embargo, el olvido de la pandemia fue más aparente que real; el dolor seguía presente, y una parte de la literatura, aunque relativamente escasa, recogió la magnitud de la tragedia, el miedo, la angustia y el horror que la pandemia produjo en las personas (Outka, 2020). Cuando la enfermedad se menciona, el resultado es profundamente perturbador: "Todos han estado enfermos de gripe. Hemos estado aquí asediados. Todos la han tenido, y nunca sabes quién será el próximo. Parece que los más fuertes son los primeros", escribió Thomas Wolfe (2008, p. 436) en 1929.

Las historias de quienes sufrieron y sobrevivieron a la pandemia de 1918 fueron recogidas muchas décadas después (Collier, 1974; Bristow, 2012; Arnold, 2018); en ellas se describen las procesiones de cadáveres, los funerales múltiples, la angustia de ser el siguiente o la alegría por sobrevivir a la guerra, mezclada con la tristeza de volver y encontrarse con la pérdida de un ser amado. La mortalidad fue rápida, brutal, masiva, pero el impacto emocional y psicológico de la tragedia, y la memoria de la pérdida se vivieron y sobrellevaron en la intimidad del espacio doméstico. El dolor de la pérdida individual quedó escondido bajo la pérdida colectiva por la Gran Guerra: socialmente, las muertes en míseros camastros no podían compararse ni asumirse como iguales a las heroicas caídas en combate, que se superaron en sociedad, con la solemnidad de los monumentos y cementerios de guerra, lo cual permitió dar paso a un nuevo tiempo.

Por lo contrario, las otras víctimas, muertas por la pandemia, quedaron ocultas bajo gruesas capas de silencio. No existen memoriales ni monumentos en su memoria, salvo unos pocos, en su mayoría erigidos durante los últimos años, a la luz del centenario de la catástrofe y casi siempre por iniciativa particular, como en Barre (Vermont, Estados Unidos) o en el Pukeahu National War Memorial Park (Wellington, Nueva Zelanda). Este último no solamente está dedicado a quienes murieron, sino también a quienes los cuidaron; constituye además un recordatorio de que la investigación de las enfermedades 
infecciosas ayuda a proteger a las generaciones futuras. Reza la lápida: "nunca serán olvidados", aunque lo fueron durante casi cien años.

En aquella época, el olvido hizo que el sufrimiento se interiorizara, lo cual tuvo graves consecuencias psicológicas para las personas. Las secuelas del confinamiento, del aislamiento o de la muerte provocaron desórdenes mentales y suicidios, e incluso asesinatos causados por el llamado "delirio de la influenza", que pretendía evitar, con la muerte, la “otra” muerte, mucho más agónica, por la enfermedad. En un estudio realizado en Noruega sobre el impacto psicológico de la pandemia, se demuestra que, en los seis años siguientes, el número de primeros ingresos por trastornos mentales asociados a ella se incrementó 7.2 veces por año (Mamelund, 2010, p. 30). A largo plazo, los efectos psicológicos y fisiológicos de la pandemia siguieron resonando durante el siglo XX en los indicadores económicos, sociales, demográficos y de salud (Almond, 2006; Ogasawara, 2018; Helgertz \& Bengtsson, 2019).

En 2020, la muerte centrada de momento en nuestros ancianos ha dejado países de adultos huérfanos y niños sin abuelos, cuyo duelo les ha sido negado por las medidas de confinamiento. Las secuelas psicológicas inevitablemente aflorarán más pronto que tarde, y tienen un precio que se incrementará con el tiempo. Aunque el conocimiento médico sobre estas enfermedades es mayor que en 1918, al igual que los recursos de los sistemas de salud, la relación del conjunto de la población con la enfermedad y la muerte es mucho menor que entonces, lo que nos hace más vulnerables a padecer este tipo de dolencias. Su tratamiento es un reto que es necesario abordar lo antes posible.

\section{CONSIDERACIONES}

La pandemia de covid-19 nos ha devuelto a la realidad. La naturaleza es terca en mostrar nuestra falta de humildad, en este caso de aquellos que pensaban, sobre todo en las sociedades occidentales, que el desarrollo tecnológico alcanzado nos mantenía al margen de las epidemias, de esas lejanas enfermedades propias del pasado o de países subdesarrollados. Que pandemias como el SIDA se hayan convertido en una enfermedades crónicas tampoco ha ayudado. Durante años, la ciencia alertó de una posible pandemia sin ser escuchada. Como dice un viejo dicho, "sólo nos acordamos de Santa Bárbara cuando truena”, pero esa desatención tiene un precio. Aunque los medios para prepararse son en la actualidad infinitamente mayores que en 1918, la falta de reacción 
ha sido parecida, es decir, lenta, y sigue estando muy por detrás de la evolución de la enfermedad.

En un mundo interconectado, con acceso casi ilimitado a la información y una mayor y más extendida educación, en estos tiempos se produce la paradoja de que, más que una ventaja, esto parece una dificultad para aplicar las medidas necesarias para combatir la pandemia. La sobresaturación de información, en muchas ocasiones errónea, ha conseguido que ésta se convierta en "música de ascensor": casi nadie la escucha. En 1918, el acceso a la información era limitado y el analfabetismo dominante; quizás, por ello, la población estaba consciente de su propia ignorancia y, en consecuencia, las autoridades gozaban de un ascendiente que en la actualidad se ha perdido o se ha diluido.

De igual modo, en 1918 la sociedad estaba mucho más acostumbrada que actualmente a la enfermedad, la muerte y el duelo; éstas formaban parte de su cotidianeidad. Las tasas de mortalidad infantil eran muy elevadas y las epidemias recurrentes, con su cuota de fallecidos. Eran poblaciones recias, diríamos, y, aun así, las consecuencias psicológicas de la pandemia perduraron durante años. El aislamiento, el sufrimiento, la incertidumbre y la muerte no se aceptan de buen grado, porque nadie está preparado para un hecho así.

El contexto histórico de 1918 era muy distinto al actual y, sin embargo, parece que los errores se repiten en una especie de déjà vu centenario. Las mismas medidas provocan reacciones semejantes en los mismos sectores de la población, y los países se defienden -y justifican- con argumentos parecidos. Si la pandemia de 1918 puso en evidencia las limitaciones y déficits de aquella sociedad, en 2020 nos ha puesto ante un espejo delante del cual despertamos mirándonos el ombligo. Los paralelismos con 1918 han servido más para asegurar las diferencias, que para aprender de los errores, en la fatua certeza de nuestras capacidades.

Es posible que esta experiencia sirva para corregir algunos de los problemas que han contribuido a propagar la enfermedad. O quizás no. Las catástrofes son fenómenos abruptos que irrumpen en nuestras vidas y centran, momentáneamente, la atención y los esfuerzos, pero, una vez que han pasado, como demuestra la amnesia de 1918, se olvidan rápidamente. El reto es evitarlo y aprender de los errores cometidos. Se trata, en suma, de una oportunidad para prepararse mejor de cara a la próxima pandemia, que seguro llegará.

La pandemia de covid-19 sigue condicionando la vida cotidiana. En algunos países, está en ascenso, en otros desciende, pero en la mayoría "desescala" con inusitada y suicida rapidez, bajo el apremio de los efectos negativos de la enfermedad sobre la economía, 
que prima sobre cualquier otra consideración. La posibilidad de que, por tiempo indeterminado, nos mantengamos en un constante rebrote de casos y muertes es una realidad, tan solo condicionada por la efectividad que puedan tener las vacunas y su distribución masiva. El tiempo lo dirá. Los gobiernos insisten en que ahora sí están preparados, pero ante los rebrotes, que se multiplican, demuestran una y otra vez su incapacidad de previsión. Siguen yendo por detrás de la enfermedad. Ni siquiera ahora se aprende.

\section{REFERENCIAS}

Acuña Soto, R., Castañeda, L. \& Chowell, G. (2011). A perspective on the 2009 A/H1N1 influenza pandemic in Mexico. Mathematical Biosciences and Engineering, 8(1), pp. 223-238.

Adja, K., Golinelli, D., Lenzi, J., Fantini, M. P. \& Wu, E. (2020). Pandemics and social stigma: Who's next? Italy's experience with COVID-19. Public health, 185, pp. 39-41.

Almond, D. (2006). Is the 1918 Influenza Pandemic Over? Long-term Effects of In Utero Influenza Exposure in the Post-1940 U.S. Population. Journal of Political Economy, 114(4), pp. 672-712.

Álvarez, A., Carbonetti, A., Carrillo, A. M., Filho, C. B., De Souza, C. M. C., Bertucci, L. M. \& Azevedo, N. (2009). The flu far and near: Comparing the 1918 and 2009 pandemics. Historia, Ciencias, Saude - Manguinhos, 16(4), pp. 10651113.

Arnold, C. (2018). Pandemic 1918: Eyewitness Accounts from the Greatest Medical Holocaust in Modern History. New York: St. Martin's Press.

Bristow, N. K. (2012). American Pandemic: The Lost Worlds of the 1918 Influenza Epidemic. New York: Oxford University Press.

Brittain, V. (1935). Testament Of Youth: An Autobiographical Study Of The Years 19001925. London: Victor Gollancz Ltd.

Cheng, V. C., Lau, S. K., Woo, P. C. \& Yuen, K. Y. (2007). Severe acute respiratory syndrome coronavirus as an agent of emerging and reemerging infection. Clinical microbiology reviews, 20(4), pp. 660-694.

Collier, R. (1974). The Plague of the Spanish Lady: The Influenza Pandemic of 1918-1919. New York: Atheneum. 
COnACYT-CentroGeo-GeoInt-DataLab (2020). Covid 19 México: Gobierno de México. Recuperado de https: / / bit.ly/3c9JpWM.

Crosby, A. W. (2003). America's Forgotten Pandemic: The Influenza of 1918. $2^{\mathrm{a}}$ ed. Cambridge: Cambridge University Press.

Crosby, A. W. (1989). America's Forgotten Pandemic: The Influenza of 1918. Cambridge: Cambridge University Press.

Cuenya, M. A. (2014). México ante la pandemia de influenza de 1918: encuentros y desencuentros en torno a una política sanitaria. Astrolabio Nueva Época: Revista digital del Centro de Investigaciones y Estudios sobre Cultura y Sociedad, 13, pp. 38-65.

Cuenya, M. A. (2010). Reflexiones en torno a la pandemia de influenza de 1918. El caso de la ciudad de Puebla. Desacatos. Revista de Antropología Social, 32, pp. 145-158.

DOF. (2020, marzo 30) Acuerdo por el que se declara como emergencia sanitaria por causa de fuerza mayor, a la epidemia de enfermedad generada por el virus Sarscov2 (Covid-19). Diario Oficial de la Federación. Recuperado de https: / / cutt.ly/5ku0Zsx.

DDCM (1918. octubre 17). Diario de los Debates de la Cámara de Diputados del Congreso de los Estados Unidos Mexicanos. Leg. XXVIII, Año I, $\mathrm{n}^{\mathrm{o}}$ 50. Recuperado de https: / / cutt.ly/OkuONOj.

EL ESPAÑOL (2020, junio 16). Más de 8.160 ancianos de las residencias de Madrid han muerto durante la pandemia de Covid-19. Recuperado de https: / / cutt.ly/nkoPRQG.

ERKorekA, A. (2009). Origins of the Spanish Influenza pandemic (1918-1920) and its relation to the First World War. Journal of molecular and genetic medicine: an international journal of biomedical research, 3(2), pp. 190-194.

García Sastre, A. \& Whitley, R. J. (2006). Lessons Learned from Reconstructing the 1918 Influenza Pandemic. The Journal of Infectious Diseases, 194(Suppl.2), pp. S127-S132.

GPMB (Global Preparedness Monitoring Board) (2019). Informe anual sobre preparación mundial para las emergencias sanitarias: "Un mundo en peligro". Recuperado de https: / / cutt.ly/ykoIJ3u.

Graham, R. L., Donaldson, E. F. \& Baric, R. S. (2013). A decade after SARS: strategies for controlling emerging coronaviruses. Nature Review Microbiology, 11(12), pp. 836-848. 
Helgertz, J. \& Bengtsson, T. (2019). The Long-Lasting Influenza: The Impact of Fetal Stress During the 1918 Influenza Pandemic on Socioeconomic Attainment and Health in Sweden, 1968-2012. Demography, 56, pp. 1389-1425.

Hernández Bringas, H. (2020). Mortalidad por COVID-19 en México. Notas preliminares para un perfil sociodemográfico. México: Centro Regional de Investigaciones Multidisciplinarias, UNAM. Recuperado de https: / / cutt.ly/fkiwzT3.

Hoppe, T. (2018). "Spanish Flu": When Infectious Disease Names Blur Origins and Stigmatize Those Infected. Am J Public Health, 108(11), pp. 1462-1464.

IbARRA, J. (2020, marzo 16). El Vive Latino, especie de burbuja ajena a los problemas. La Jornada. Recuperado de https://cutt.ly/ukievpu.

Johnson, N. P. \& Mueller, J. (2002). Updating the accounts: global mortality of the 1918-1920 'Spanish Influenza' pandemic. Bulletin of the History of Medicine, 76(1), pp. 105-115.

Justo, D. (2020, febrero 27). Los gráficos sobre el coronavirus que invitan al optimismo. Cadena SER. Recuperado de https: / / cutt.ly/1 ku5Som.

Mamelund, S. E. (2010). The Impact of Influenza on Mental Health in Norway, 18721929. Historical Influenza Pandemics: Lessons Learned. Meeting and Workshop Abstracts, May 2010. Copenhagen; Carlsberg Academy, Recuperado de https://cutt.ly/Eku59YV.

Martín, Y. (2020, febrero 27). Hay más muertes por gripe y no crean tanta alarma como el coronavirus. El Día, la opinión de Tenerife. Recuperado de https://cutt.ly/Qku0QZ6.

Menachery, V., Yount, B., Debbink, K., Agnihothram, S., Gralinski, L. E. Plante, J. A. ET AL. (2015). A SARs-like cluster of circulating bat coronaviruses shows potential for human emergence. Nature Medicine, 21, pp. 1508-1513.

MiTjÁ, O. (2020, febrero 24) COVID-19: hay que esperar lo mejor y estar preparados para lo peor. Agencia SINC. Recuperado de https:/ / cutt.ly/lku0nFk.

MSCBS (Ministerio de Sanidad, Consumo y Bienestar Social, Gobierno de España). Actualizaciones. Enfermedad por el coronavirus (COVID-19). Centro de Coordinación de Alertas y Emergencias Sanitarias (CCAES). Recuperado de https://cutt.ly/Gku0cgJ.

Newsholme, A. (1919). Discussion on Influenza. Proceedings of the Royal Society of Medicine, 12, issue: Gen Rep, pp: 1-18. 
Ogasawara, K. (2018). The long-run effects of pandemic influenza on the development of children from elite backgrounds: Evidence from industrializing Japan. Economics \&Human Biology, 31, pp. 125-137.

OMS (2020). Coronavirus disease 2019 (COVID-19) Situation Report - 51. Recuperado de https: / / cutt.ly/2ku0R0w.

OutKA, E. (2020). Viral Modernism. The Influenza Pandemic and Interwar Literature. New York: Columbia University Press.

PÉreZ V., C. (2006). La dieta del náufrago. En Nelly, R. (Ed.), Políticas y estéticas de la memoria (pp. 189-198). Santiago de Chile: Editorial Cuarto Propio.

Phillips, H. (2014). The Recent Wave of 'Spanish' Flu Historiography. Social History of Medicine, 27(4), pp. 789-808.

PHWR (1918a). Public Health Weekly Reports for JUNE 21, 1918. (1918). Public health reports (Washington, D.C.: 1896), 33(25), 1003-1049.

PHWR (1918b). Public Health Weekly Reports for SEPTEMBER 13, 1918. (1918). Public health reports (Washington, D.C.: 1896), 33(37), 1537-1574.

Pretel, E. A. \& Escudero, J. (2020, marzo 21). ¿Mano dura china? No, gracias: así están derrotando estas democracias al coronavirus. El Confidencial. Recuperado de https: / / cutt.ly/sku6hI5.

Secretaría de Salud (2020). Comunicado Técnico Diario COVID-19. 30/03/2020. México: Gobierno de México. Recuperado de https: / / cutt.ly/lku05KJ.

Simonsen, L., Chowell, G., Andreasen, V., Gaffey, R., Barry, J., Olson, D. \& VIBOUD, C. (2018). A review of the 1918 herald pandemic wave: Importance for contemporary pandemic response strategies. Annals of Epidemiology, 28(5), pp. 281-288.

Susser, M., Watson, W. \& Hopper, K. (1985). Sociology in Medicine. Oxford: Oxford University Press.

TAubenberger, J. K. \& Morens, D. M. (2006). 1918 Influenza: the mother of all pandemics. Emerging infectious diseases, 12(1), pp. 15-22.

VALDEZ, R. (2002). La pandemia de gripe. Sinaloa, 1918-1919. Elementos, Ciencia y Cultura, 9(47), pp. 37-43.

VAn der Giessen, J. W. B., Isken, L. D. \& Tiemersma, E. W. (2004). Zoonoses in Europe: a Risk to Public Health. Bilthoven, the Netherlands: National Institute for Public Health and the Environment. 
Wever, P. C. \& VAn Bergen, L. (2014). Death from 1918 pandemic influenza during the First World War: a perspective from personal and anecdotal evidence. Influenza and other respiratory viruses, 8(5), pp. 538-546.

WhiteHEAD, M. (2000). The concepts and principles of equity and health. Copenhagen: World Health Organization Regional Office for Europe.

Wolfe, TH. (2008 [1929]). Look Homeward, Angel. New York: Scribner. 